\title{
VIVENCIAS DE GRADUANDOS E FISIOTERAPEUTAS NO CONTEXTO DOMICILIÁRIO À PESSOA IDOSA FRAGILIZADA
}

Tatiane Dias Casimiro Valença ${ }^{1}$ Luzia Wilma Santana Da Silva²

resumo

Este estudo é oriundo de investigação qualitativa, assentado em multitécnica e se propõe a conhecer as vivências de graduandos e profissionais fisioterapeutas no cuidado domiciliário à pessoa fragilizada e sua família. Foi realizado em quarto instituições de ensino superior do estado da Bahia, com 43 participantes, sendo 28 graduandos e 15 fisioterapeutas. Os dados foram triangulados e compreendidos à luz da análise de conteúdo. Os resultados evidenciaram que o ambiente domiciliar é, por vezes, um espaço desconhecido da vivência acadêmica dos graduandos e profissionais fisioterapeutas, pois expressam sentimentos de insegurança e medo para atuarem nesse contexto por carência na formação acadêmica. Destacam a necessidade de reformulação dos componentes curriculares à

1 Graduada em Fisioterapia. Doutora em Memória: Linguagem e Sociedade/UESB. Professora da Universidade Estadual do Sudoeste da Bahia (UESB), vinculada ao Departamento de Saúde 1. E-mail: tativalenca26@gmail.com.

2 Graduada em Enfermagem. Pós-Doutora em Enfermagem (NUCRON-PEN/UFSC). Professora da Universidade Estadual do Sudoeste da Bahia (UESB), vinculada ao Departamento de Saúde 2. E-mail: luziawilma@yahoo.com.br. 
inserção do processo formador ao contexto comunitário-domiciliar mais proximal, cujos saberes os potencializam de referências teórico-práticos sobre família, envelhecimento e comunidade.

palavras-chave

Serviço de Assistência Domiciliar. Fisioterapia. Envelhecimento. Família.

\section{Introdução}

O atendimento domiciliar tem sido uma estratégia amplamente difundida no cenário mundial, tendo como pontos fundamentais o cliente, a família, o contexto domiciliar, o cuidador e a equipe multiprofissional. Não se trata de algo novo nas discussões do sistema de saúde e social. Nos anos 2000, estudiosos sinalizam a necessária inserção desta estratégia em nosso meio de forma impactante, apontando entre as causas a transição demográfica - o envelhecimento populacional cada vez mais acentuado; a mudança no perfil epidemiológico da população com o aumento das Doenças Crônicas Não Transmissíveis (DCNT); os custos do sistema hospitalar cada vez mais elevado à complexidade das doenças no envelhecimento; o interesse dos profissionais de saúde por novas áreas de atuação; a exigência por maior privacidade, individualização e humanização da assistência à saúde, vinculada pelos meios de comunicação no contexto atual e sua exigência na maior aproximação à integração entre profissionais de saúde e o sujeito da ação do cuidado - idoso e família (DUARTE; DIOGO, 2005).

Corroboram com esta estratégia Almeida et al. (2006), Puccini e Cecílio (2004), quando descrevem que esta forma de atendimento possibilita uma assistência mais integrada à medida que vão se desenvolvendo relações humanizadas por meio do vínculo proximal entre profissionais, idoso e família. Isso contribui para a melhoria da qualidade do viver humano e ser saudável da pessoa idosa em sua complexidade e multidiversidade.

Embora se torne consenso que a assistência domiciliária venha potencializar o cuidado humano dos serviços de saúde (TORRES et al., 2009), exige-se dos profissionais desta área, um novo olhar sobre a dimensionalidade das relações para sua inserção neste contexto (SILVA et al., 2008; LOPES, 2007). Entendendo ser imprescindível a aquisição de saberes-fazeres do profissional sobre o sistema familiar de modo a praticar o exercício de uma práxis proximal 
resolutiva, compreende-se que o cuidar a ser desenvolvido enovela todo um contexto humano, a família e seus membros, para além dos fatores de desvio de saúde nas situações de pessoas idosas dependente de cuidados, e também os profissionais de saúde.

Nesse sentido, Romanholi e Cyrino (2012), expõem que a partir do atendimento domiciliar e da narrativa do outro, o profissional de saúde, desde a sua graduação, precisa ser mobilizado para construir conhecimentos e dar significados ao processo saúde-doença da pessoa no contexto comunitário. Esses autores destacam ainda ser preciso colocar em evidência na pauta de cuidadosa formação profissional, a vivência proximal às demandas sócio-comunitárias, a exemplo de cuidados à saúde ao alcance da qualidade de vida das pessoas.

Logo, mostra-se necessário que o fisioterapeuta desenvolva capacidade para exercer um olhar perscrutador a pessoa no contexto de sua inter-relação, por assim dizer, sua família e rede social vincular. O olhar perscrutador do ser cuidador deve ser multifacetado, social, político, psíquico, filosófico e cultural, assim não míope na produção de um "ver" fragmentado e superficial ao ser idoso-família-comunidade (SILVA et al., 2012). Contudo, um desafio se mostra para o fisioterapeuta - inserir-se no ambiente domiciliar para o cuidado à saúde da pessoa idosa fragilizada, pois a sua formação ainda se encontra centrada em amplo aspecto no individual e para a doença (VALENÇA, 2011).

Muitos profissionais fisioterapeutas revelam dificuldades para adentrar o espaço domiciliar e realizar o cuidado, para além do aspecto fisiológico do cliente. Essa é uma problemática discutida por Almeida et al. (2006), que salientam a necessidade de constructos sobre a família na formação do fisioterapeuta de modo a incorporação dos saberes antropológicos e socioambientais, os quais, promoverão um intervir para garantir o cuidado integral ao sujeito/família na práxis fisioterapêutica. Assim, diante de tais evidências, este estudo tem por objetivo conhecer as vivências de graduandos e profissionais fisioterapeutas no cuidado domiciliário à pessoa fragilizada e sua família.

\section{Metodologia}

Estudo de natureza qualitativa, exploratória, descritiva e documental, tendo como cenários quatro instituições de ensino superior (IES) do Estado da Bahia, sendo 01 pública e 03 privadas. Os critérios selecionados foram os seguintes: 1) IES com cursos de Fisioterapia com dez ou mais anos de implantação e 2) IES com cinco ou mais anos de reconhecimento junto aos órgãos competentes. 
O estudo contou com 28 graduandos e 15 fisioterapeutas. Para o alcance dos discentes obteve-se dos colegiados dos cursos das IES pesquisadas o número de graduandos do último semestre, segundo os critérios de inclusão do estudo: 1) graduando que estava cursando o último semestre do curso de Fisioterapia; 2) graduando com práticas no atendimento em ambiente domiciliar durante o curso; 3) aceitaram participar do estudo. Foram contatados 65 discentes, sendo 28 entrevistados após sorteio aleatório e o fechamento da amostra, seguiu-se a saturação dos dados (POLIT; BECK, 2004; MILES; HUBERMAN, 1984).

Para o alcance desta etapa da pesquisa, primeiramente foi realizado contato por telefone e/ou mensagem eletrônica via rede mundial de computadores para os coordenadores dos cursos de graduação em Fisioterapia das IES selecionadas, informando-os dos objetivos do estudo e solicitando autorização para realização da pesquisa nas IES. A partir da posse da autorização, passou-se a realização de visitas às IES. Essa etapa visou, além das entrevistas aos discentes, o estudo das ementas e planos de curso das disciplinas da componente curricular para a etapa de inquérito documental da pesquisa.

Assim, durante as visitas, foram contatados os graduandos, efetivando o convite para participação no estudo. Todos anuentes assinaram Termo de Consentimento Livre e Esclarecido (TCLE). As entrevistas foram realizadas na Clínica Escola de Fisioterapia das IES durante os intervalos de aulas-atendimento aos pacientes.

Já a coleta de dados com os profissionais fisioterapeutas ocorreu após identificação dos Serviços de Saúde que realizavam atendimento fisioterapêutico domiciliar, nas cidades de inserção das IES selecionadas. Foram contatados por telefone 19 profissionais, e destes 04 não aceitaram participar da pesquisa. Aos demais 15 profissionais egressos das IES cenários da pesquisa que aceitaram colaborar com informações foram agendadas visitas para apresentação de pesquisa e assinatura do TCLE. Durante o encontro agendado foi realizada a entrevista de forma individualizada nas unidades públicas de trabalho ou consultórios dos profissionais.

Os instrumentos de coleta de dados foram: 1) Entrevista semiestruturada; 2) Inquérito Documental; e, 3) Pesquisa Documental. Estes subsidiados por meio da observação participante com registro em diário de campo, utilizando o recurso da memória recente. Tais instrumentos se complementaram e foram validando um ao outro, conforme nos ensina Igea (1995), quando refere que diversos métodos para coleta de dados permitem percorrer o olhar sobre várias perspectivas da mesma situação, obtendo informações de diferentes naturezas, podendo realizar a comparação entre os diversos elementos com maior fidedignidade, sendo esse o ponto-chave nessa pesquisa. 
A escolha pela entrevista semiestruturada apoiou-se no pensar de Flick (2009) e Triviños (2009). Os autores descrevem que esse instrumento permite a descrição, explicação e compreensão global de um fenômeno pesquisado, possibilitando gerar uma interface de comunicação entre o pesquisador e o informante acerca de um tema específico em que o entrevistador tem liberdade de acrescentar novas perguntas, objetivando esclarecer pontos que considere relevantes aos objetivos do estudo.

As questões da entrevista foram elaboradas a partir das inquietações que desencadearam a busca da temática, do Referencial Teórico e do Estado da Arte. Visavam suscitar verbalizações que expressasse o modo de pensar e agir dos participantes, sentimentos, atitudes, motivos, intenções e valores sobre a profissão, assim, uma possibilidade de maior aprofundamento à temática.

Para os graduandos, a seguinte questão foi feita: você está preparado para ter acesso ao ambiente domiciliar da pessoa idosa e vivenciar as relações familiares presentes nesse ambiente? E, para os profissionais Fisioterapeutas, a pergunta foi: quais as principais dificuldades/facilidades o senhor(a) identifica em relação ao contexto familiar da pessoa idosa ao realizar o atendimento domiciliar?

As entrevistas foram gravadas com auxílio do gravador digital GPX, ouvida e transcrita na íntegra imediatamente após a sua realização pelas pesquisadoras, no Software Word, Windows 2010. Foi um exercício de centração e pré-análise, de modo a se constituir saberes que subsidiassem a compreensão e a cartografia das categorias, assim como o alcance da saturação dos dados. Foram identificadas e arquivadas em computador no formato Som wave, no Software Windows Media Player. Cada participante foi identificado pelo número da entrevista realizada e pelas letras P ou G (Profissional ou Graduando), sendo preservada sua fala no modo coloquial, sem correção ortográfica e/ou gramatical.

O Inquérito Documental realizado nos ementários e planos de curso das componentes curriculares das IES seguiu um roteiro estruturado que buscou averiguar a presença de conteúdos que abordassem a temática do cuidado à família. Os achados foram copiados e compilados em pasta-arquivo, compreendendo um processo de ampliação do olhar sobre a temática à transversalização dos dados.

Buscando alcançar maior entendimento, também foi realizada Pesquisa Documental que, de acordo com Apolinário (2009) e Oliveira (2002), é muito próxima da pesquisa bibliográfica, sendo o elemento diferenciador a natureza das fontes. Na pesquisa documental feita nesse estudo, analisou-se a Lei de Diretrizes e Bases (LDB); a Lei de Diretrizes Curriculares Nacionais do Curso de Graduação em Fisioterapia; a Legislação que regulamenta a profissão do Fisioterapeuta (Leis e Decretos, Código de Ética do Fisioterapeuta, Resoluções, 
Pareceres do Conselho Nacional de Educação/Câmara de Educação Superior) para obter mais informações das diretrizes estabelecidas à formação e práxis do profissional Fisioterapeuta.

O tratamento dos dados envolveu um processo dinâmico e cíclico que perpassou por idas e vindas na concepção de bricolagem. Seguiu-se três passos ou componentes de atividades concorrentes: a redução dos dados, a sua apresentação e a interpretação/verificação das conclusões (MILES; HUBERMAN, 1984).

Para a análise e interpretação dos dados foi empregada a Análise de Conteúdo, seguindo o modelo proposto por Miles e Huberman (1984), que relatam que a análise qualitativa é cíclica e implica um vaivém entre os diversos componentes. E assim, foi-se compreendendo o problema, identificando informações que não foram totalmente esclarecidas a priori, mas à medida que as entrevistas foram se desenvolvendo, iam-se ajustando uma a uma, e estas eram enriquecidas com os demais instrumentos de coleta de dados.

Esse processo se deu como uma espiral em movimento dinâmico dos instrumentos, o qual se avultava momento a momento. Além disso, ia se dando a saturação dos dados, conduzindo ao fechamento da amostra dos participantes e o alcance da fase de interpretação/verificação dos dados.

Essa fase se desenvolveu em um processo de formação, construção e reconstrução que buscou a interseção dos dados, a partir da análise compreensiva e atração do que emergiu das falas dos participantes com os demais instrumentos, constituindo, nesse momento, um mosaico interpretativo à luz da premissa teórica assentada do estudo, o que titulamos de triangulação das categorias cartográficas. A partir disso, emergiram as categorias e subcategorias de análise, sendo uma delas o objeto de discussão deste artigo, intitulada: Percepções dos graduandos e profissionais da fisioterapia: inserção no ambiente familiar da pessoa idosa.

A pesquisa recebeu aprovação pelo Comitê de Ética em Pesquisa da Universidade Estadual do Sudoeste da Bahia, Parecer nº 215/2010, CAEE: 0050.0.454.00010. O trabalho de campo ocorreu no período do mês de novembro de 2011.

\section{Resultados e Discussão}

Nesse estudo, a semântica que se desenvolveu no pensar-agir sobre atendimento domiciliar coloca-se no plano sua importância enquanto uma estratégia que contribui para o desenvolvimento de relações humanizadas, fortalecimento de vínculos recursivos entre profissionais e as pessoas da práxis do cuidado. Contudo, outro sentido se fez entoar, entendido como um grande desafio - sua implementação com efetividade na área de fisioterapia. Daqui 
procede à tendência da formação acadêmica ainda apresentar-se com maior atenção a abordagem tecnicista, na qual há fragmentação sobre o cuidado com a pessoa, que em muito é concebida em partes, em outras palavras, por sistemas decompostos, na ênfase do locomotor. Assim, há pouca ou nenhuma aproximação ao seu contexto relacional e a pessoa em sua globalidade, o que não é difícil atribuir esse resultado, tendo consequência impactante ao desejado cuidado pleno, integral, existencial e relacional.

Sobre isso, no livro Um Discurso Sobre as Ciências, Santos (2013), preocupa-se em demonstrar a importância da mudança do paradigma fragmentador para o integrador na formação dos sujeitos da ciência. Corrobora com o autor, Oliveira (2007), quando diz que uma mudança curricular nos cursos de área da saúde é capaz de produzir uma transformação de paradigmas de fazer e pensar saúde contribuindo para uma postura interdisciplinar, multiprofissional e humanística dos profissionais.

A formação acadêmica do Fisioterapeuta, de forma geral, tem se caracterizado por um processo de ensino-aprendizagem baseado na fragmentação do conhecimento. Isso acarreta em um perfil profissional baseado em uma visão de mundo cartesiana. Segundo Capra (1992), isso tende a fazer do exercício profissional a reunião de ações isoladas, individualizadas, descontextualizadas, distantes do conceito de integralidade na saúde, problemática que também encontra reconhecimento em outros estudiosos (FREITAS; MIRANDA; NERY, 2016; CECCIM, 2006; SCHMIDT, 2002).

Os destaques dos autores encontram uma especificação ulterior, uma necessidade de valoração do cuidado em sua inteireza e globalidade, estando assentado em um saber que valorize a multirreferencialidade e a subjetividade para o ser-saber-fazer às demandas da sociedade atual. Assim, requer um fisioterapeuta com atitude global, crítica diante dos problemas sociais e com perspectiva de olhar multidimensional o cuidado. Consiste de lançar luz sobre as Diretrizes Curriculares para esta profissão (BRASIL, 2002). Portanto, um novo direcionamento na formação dos profissionais fisioterapeutas que fundamente-se no cuidado a pessoa em suas necessidades de saúde e não apenas reabilitadora (FORMIGA; RIBEIRO, 2012), e também ao sistema familiar de pertencimento - um cuidado integral e subjetivo.

Sobre isso, é preciso, naturalmente, que a inserção do profissional de fisioterapia ao ambiente domiciliar se faça de forma contextual, e a esse propósito, vale ratificar o aumento do contingente humano idoso e mais idoso em nossa sociedade (IBGE, 2011), que mesmo diante do processo de envelhecimento natural, demandará cuidados. 
Nesta perspectiva, o ambiente domiciliar é o local para práticas de saúde em que o fisioterapeuta poderá executar intervenções, podendo incluir as de natureza complexa (FABRÍCIO et al., 2004). Contudo, como dito antes, precisa estar sensível às demandas oriundas das mudanças epidemiológicas da sociedade atual, na observância às suas necessidades e, para tanto, deve saber gerenciar flexibilidade ao sistema familiar à construção de um processo de confiabilidade e respeito mútuo (SILVA; DA ROS, 2007).

Estreitando a discussão para o identificado nas falas dos graduandos de fisioterapia, temos que, esses têm pouca experiência no relacionamento interpessoal profissional-paciente-família com referência às componentes curriculares estarem mais direcionadas para os espaços do hospital e da clínica. Portanto, o ambiente domiciliar mostra-se como desconhecido no contexto de atendimento, o que tem estreita relação com os sentimentos de medo e insegurança propalados. Trata-se de uma evidência que pode influenciar o processo de cuidado integral à pessoa idosa e à família quando da profissionalização como aponta Gonçalves e Melo (2011).

Já no caso dos fisioterapeutas, a transição da sala de aula para o contexto prático na vida profissional foi um momento importante, por ser a etapa de aplicação do conhecimento e do aperfeiçoamento de habilidades em uma situação real. Não obstante, o momento de junção do saber com o fazer para um agir profissional consciente, crítico e reflexivo foi conflitante. Nesse particular, ressalta Marinho e Fiorelli (2005) que o fisioterapeuta ao adentrar o domicílio poderá se ver envolvido em conflitos familiares capazes de colocá-lo em situação delicada perante o grupo ou o idoso a ser atendido.

A síntese compreensiva sobre estes dois universos, graduandos - profissionais de fisioterapia, evidencia que eles não se consideram suficientemente preparados, para adentrarem o ambiente domiciliar e manter um processo relacional de cuidados com a pessoa idosa e família, como se pode observar nas falas:

É uma situação que deixa a gente meio temerosa porque é pouco explorada. Por não conhecer muito essa relação do profissional com a família no domicílio, por não ter muita prática na faculdade fica um pouco de insegurança no que a gente vai encontrar lá no domicílio. (G10A)

Uma das dificuldades que passei foi a falta de uma experiência maior com o ambiente domiciliar e com a família do paciente durante a graduação. Isso traz certo medo quando você tem que ir fazer o atendimento em domicílio. (P4B) 
O encontro com o não experimentado é, por vezes, ameaçador e evoca a vulnerabilidade do ser ao exercício profissional, em relação ao contato com o outro (família) e o estabelecimento de vínculos relacionais. Além disso, ao observarmos os locais de aprendizagem das IES, o domicílio se mostra como um ambiente pouco explorado, o que, ratifica os sentimentos expressos nas falas. Assim, torna-se um desafio para o fisioterapeuta inserir-se nesse ambiente para o cuidado à saúde da pessoa idosa fragilizada, como também, formar parcerias com seus familiares (ALMEIDA et al., 2006).

A este respeito, Guimarães (2007) enuncia que a relação do fisioterapeuta com o paciente e sua família será marcada ao longo de toda sua atuação profissional pela imperfeição da vida, pela dor física e psíquica, pelo corpo e suas vicissitudes, e que, aprender a lidar com essa relação é fundamental para o profissional, pois o cuidar exige interação com outro. O cuidado não é unidirecional, ele é formado e construído tanto pelo ser que cuida quanto pelo ser que é cuidado, sendo construído por relações intersubjetivas permeadas por sensibilidade e emoções, e a ausência destes, tornaria as relações frias e vazias, assim como o próprio (des)cuidado. Nesse contexto, o fisioterapeuta, além do saber técnico-científico, precisa desenvolver o cuidado intersubjetivo para garantir a integralidade e qualidade de sua ação (BAGGIO; MONTICELLI; ERDMANN, 2009).

Segundo Frade e Meira (2012), ao ampliar-se o entendimento de educação para além dos muros da escolarização formal e pensando nas múltiplas interações sociais ao participar do mundo, percebemos o quanto estamos em contínuo processo de aprendizagem uns com os outros. Portanto, é necessário que durante a formação do fisioterapeuta o eu self possa abrir-se para o nós, levando a compreensão por parte do profissional que cada membro do sistema familiar é um "eu", e que o nós - profissional, idoso, família - é que irá proporcionar o cuidado integral ao ser idoso.

Trata-se, portanto, do princípio de recursividade, o fisioterapeuta, ao adentrar o ambiente domiciliar não deve buscar conhecer o sistema familiar como algo estático e definitivo. Como afirmam Liberato et al. (2008), qualquer profissional ao adentrar no mundo da família estará em constante movimento, em mutação, pois, estar-se-á diante de um sistema constituído por diversos "eu", cada um com seu saber e jeito de ser, necessitando que seja entendido cada um na sua individualidade, mas ainda, como um sistema que influencia e sofre influência do outro, assim, no "nós", ou seja, em sua globalidade. Desse modo, a formação do fisioterapeuta deverá estar voltada à saúde da população comprometendo-a em sua realidade contextual, relacional e social.

Outro aspecto que também desencadeou temor e insegurança para os profissionais e graduandos, referiu-se ao fato de que o ambiente domiciliar é 
um local onde o paciente e a família têm o controle - seu espaço de poder; seu espaço de relação e pertencimento. O profissional ao adentrar esse espaço para realizar as condutas terapêuticas, muitas vezes, as faz sob o olhar atento do familiar. Aquele não é o espaço do seu consultório, território no qual acredita ser de seu domínio e conforto, onde exerce o controle, mas antes o lugar de poder do outro. Lugar que lhe traduz estranheza.

O domicílio é um lugar estranho para o fisioterapeuta e é o lugar do paciente, onde ele está com sua família. (G1D)

Quando a gente vai atender na casa do paciente ali não é nosso território, nós somos estranhos ali, nada nos pertence ali. $\bigcirc$ paciente e a família é quem domina aquele espaço. Então se eu vou para um lugar estranho eu tenho que buscar conhecer. (P2C)

Noutros discursos, os graduandos revelaram ser o tempo um bom aliado para o preparo de suas capacidades à inserção no ambiente familiar, por acreditarem que ao experienciar sucessivas práticas no domicílio, estarão mais habilitados para os cuidados naquele ambiente:

A gente vai se preparando com o tempo, com as vivências. Eu acho assim, com o tempo a gente vai aprendendo [...] preparada eu não estou. A gente vai se preparando com a vivência. (G8A)

Pela experiência passada na universidade não tenho experiência ou preparo para entrar no domicílio e atender o paciente e ainda trabalhar com toda a família. A experiência vai vir depois, na atuação [...] a gente pode estar buscando na prática diária. (GTA)

De acordo com o Art. $4^{\circ}$, inciso VI, das Diretrizes Curriculares Nacionais do Curso de Graduação em Fisioterapia (BRASIL, 2002), os profissionais devem ser capazes de aprender continuamente, tanto na sua formação, quanto na sua prática. Portanto, novos conhecimentos devem ser adquiridos, trocados e repassados, seja durante a graduação, seja na prática diária dos egressos, pois diante da mudança crescente no perfil demográfico e epidemiológico da população brasileira, o fisioterapeuta deve estar atualizado para conseguir acompanhar a demanda do cuidado que se mostra.

Igualmente, relatam Soares e Sadigursky (2009), que o profissional precisa apresentar competência não só nos aspectos técnico-científicos, mas também, no componente subjetivo e individual que depende das vivências adquiridas 
no cotidiano do ser-existir de cada profissional. Assim, nos discursos dos profissionais fisioterapeutas o tempo é um auxiliador e a idade, com a maturidade, um diferencial para a aproximação aos cuidados no contexto domiciliar:

Eu saí da faculdade muito imaturo. Só com o tempo, com a experiência de atender diferentes pessoas, diferentes realidades é que eu fui ganhando segurança e aprendendo a lidar com as dificuldades, com os imprevistos. (P2)

Quanto mais precocemente os graduandos entrarem em contato com a realidade de o ambiente domiciliar e as relações familiares, mais precocemente serão experimentadas as experiências com relação à atuação crítica reflexiva frente às demandas do contexto domiciliário. Por isso, é necessário viabilizar o espaço comunitário na formação acadêmica o mais cedo possível, o que exige, na realidade atual, reformulação das componentes curriculares dos cursos de graduação em Fisioterapia das IES estudadas.

Portanto, ao escutar-perscrutando a fala dos participantes urge como necessário repensar o processo formador como aquele que possa entremear a relação interpessoal profissional-idoso-família. Trata-se de perspectivar uma tessitura entre os saberes técnico-científicos aos sociais-humanísticos, de modo a minimizar/extinguir os medos, a insegurança e a percepção de falta de "amadurecimento" psicocognitivo para adentrar o espaço domiciliar e empreender o cuidado conjunto fisioterapeuta-família no direcionamento da promoção da saúde do sistema familiar em sua inteireza e globalidade.

\section{Considerações Finais}

A compreensão assentada nos dados revelados no estudo acena para uma urgente e necessária reforma curricular nas IES do Estado da Bahia estudadas, as quais encontram eco no cenário nacional evidenciados pelo estado da arte, sendo identificado que a formação do fisioterapeuta precisa ser redefinida para o alcance da pessoa idosa e da família no contexto comunitário e domiciliar, pois, a formação dessa categoria profissional ainda se encontra voltada ao cenário clínico-hospitalar. Além disso, também foi evidenciada a necessidade de um processo formador que convirja ao pensar integrador, cujas fronteiras disciplinares sejam abertas às ciências sociais e humanas na transversalidade com as ciências biológicas. Os graduandos e profissionais fisioterapeutas revelaram que o ambiente domiciliar é, por vezes, um espaço desconhecido a sua vivência. E, nessa situação, sentimentos enovelados de medo, insegurança e expectativas envolvem seu ser-estar cuidador em consequência da carência de 
saberes e experiências práticas nesse cenário durante a formação acadêmica. Para enfrentarem com maior resolutividade tal situação, enunciam a necessidade da transposição da formação de uma concepção centrada na doença para uma dimensão que vise contemplar conhecimentos que atendam a pessoa da ação cuidativa na multidimensionalidade do ser em seu contexto relacional de pertencimento, sobretudo, na perspectiva de ser o cenário domiciliar o seu mais novo contexto de inserção profissional, e como tal, uma questão pontual para sua contribuição ao fortalecimento do Sistema Único de Saúde.

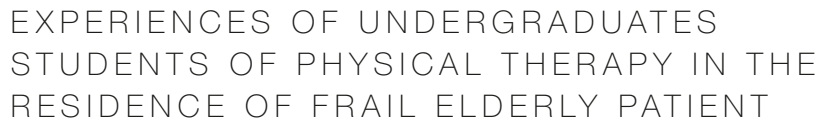

\section{abstract}

This study is based on qualitative research based on multi technics and aims to know the experiences of undergraduate and professional physiotherapists in the home care of the frail person and his/her family. It was held in four institutions of higher education in the State of Bahia with 43 participants, of which 28 were undergraduates and 15 physiotherapists. The data were triangulated and understood in light of the content analysis. The results showed that the home environment is sometimes an unknown area of the academic experience of undergraduates and physiotherapists who express feelings of insecurity and fear to act in this context due to lack of academic training. They emphasize the need to reformulate the curricular components to the insertion of the formation process into the more proximal community-domicile context, whose knowledges empower them with theoretical-practical references on family, aging and community.

keywords

Home Care Service. Physiotherapy. Aging. Family.

referências

ALMEIDA, Leila Graziela et al. Promover a vida: uma modalidade da fisioterapia no cuidado à saúde de idosos. Revista Saúde.com, Jequié, v. 2, n. 1, p. 50-55, 2006.

BAGGIO, Maria Aparecida; MONTICELLI, Marisa; ERDMANN, Alacoque Lorenzini. Cuidando de si, do outro e "do nós" na perspectiva da complexidade. Revista Brasileira de Enfermagem, Brasília, DF, v. 62, n. 4, p. 627-631, 2009. 
BRASIL. Conselho Nacional de Educação. Câmara de Educação Superior. Resolução CNE/CES 4, de 19 de fevereiro de 2002. Institui as Diretrizes Curriculares Nacionais do Curso de Graduação em Fisioterapia. Diário Oficial da União, Brasília, DF, 4 de março de 2002. Disponível em: <http://portal.mec.gov.br/cne/arquivos/pdf/CES042002.pdf>. Acesso em: 31 jan. 2018.

CECCIM, Ricardo Burg. Equipe de saúde: a perspectiva interdisciplinar na produção dos atos terapêuticos. In: PINHEIRO, Roseni; MATTOS, Rubén Araújo de (Org.). Cuidado: as fronteiras da integralidade. 3. ed. Rio de Janeiro: IMS/UERJ, 2006.

DUARTE, Yeda Aparecida de Oliveira; DIOGO, Maria José D'Elboux. Atendimento domiciliar: um enfoque gerontológico. São Paulo: Ed. Atheneu, 2005.

FABRÍCIO, Suzele Cristina Coelho et al. Assistência domiciliar: a experiência de um hospital privado do interior paulista. Revista Latino-Americana de Enfermagem, Ribeirão Preto, v. 12, n. 5, p. 721-726, 2004.

FLICK, Uwe. Introdução à pesquisa qualitativa. 3. ed. Porto Alegre: Artmed, 2009.

FORMIGA, Nicéia Fernandes Barbosa; RIBEIRO, Kátia Suely Queiroz Silva. Inserção do Fisioterapeuta na Atenção Básica: uma Analogia entre Experiências Acadêmicas e a Proposta dos Núcleos de Apoio à Saúde da Família (NASF). Revista Brasileira de Ciências da Saúde, São Caetano do Sul, v. 16, n. 2, p. 113-122, 2012.

FRADE, Cristina; MEIRA, Luciano. Interdisciplinaridade na escola: subsídios para uma Zona de Desenvolvimento Proximal como espaço simbólico. Educação em Revista, Belo Horizonte, v. 28, n. 1, p. 371-394, 2012.

FREITAS, Elizabete Viana de; MIRANDA, Roberto Dishinger; NERY, Mônica. Parâmetros clínicos do envelhecimento e avaliação geriátrica global. In: FREITAS, Elizabete Viana de. Tratado de Geriatria e Gerontologia. 4. ed. Rio de Janeiro: Guanabara Koogan, 2016

GONÇALVES, Ronald Nascimento; MELO, Janaina Silveira. Expectativas dos universitários do curso de fisioterapia frente ao primeiro estágio prático e a reflexão da participação docente na preparação para o estágio prático. Revista Ensaios e Ciência: Ciências Biológicas, Agrárias e da Saúde, v. 15, n. 1, p. 153-69, 2011.

GUIMARÃES, Katia Burle dos Santos. Saúde mental do médico e do estudante de medicina. São Paulo: Casa do Psicólogo, 2007.

IGEA, Delio del Rincón. Técnicas de investigación en ciencias sociales. Madri: Dykinson, 1995

INSTITUTO BRASILEIRO DE GEOGRAFIA E ESTATÍSTICA. Censo demográfico 2010: questionário da amostra. Brasília, DF: Ministério da Saúde, 2011.

LIBERATO, Elizabeth Moraes et al. Convivência familiar na velhice. Revista Univap - Ciência - Tecnologia - Humanismo, São José dos Campos, v. 15, n. 27, p. 124-127, 2008

LOPES, Lídia Maria Pereira. Necessidades e estratégias na dependência: uma visão da família. Revista Portuguesa de Saúde Pública, Lisboa, v. 25, n. 1, p. 39-46, 2007.

MARINHO, Ana Paula; FIORELLI, José Osmir. Psicologia na fisioterapia. 1. ed. São Paulo: Atheneu, 2005

MILES, Matthew; HUBERMAN, Michael. Drawing valid meaning from qualitative data: toward a shared craft. Educational Researcher, v. 13, n. 3, p. 20-30, 1984

OLIVEIRA, Silvio Luiz de. Tratado de Metodologia Científica: projetos de pesquisa, TGI TCC, monografias, dissertações e teses. São Paulo: Pioneira, 2002.

OLIVEIRA, Tânia Regina Barbosa de. Interdisciplinaridade: um desafio para a atenção integral à saúde. Revista Saúde.com, Jequié, v. 3, n. 1, p. 20-27, 2007.

POLIT, Denise; BECK, Cheryl Tatano. Fundamentos de pesquisa em enfermagem. 5. ed. Porto Alegre: Ed. Artmed, 2004. 
PUCCINI, Paulo de Tarso; CECílIO, Luiz Carlos de Oliveira. A humanização dos serviços e o direito à saúde. Cadernos de Saúde Pública, Rio de Janeiro, v. 20, n. 5, p. $1342-1353,2004$

SANTOS, Boaventura de Sousa. Um Discurso sobre as Ciências. 7. ed. Porto: Edições Afrontamento, 2013

SCHMIDT, Luciana Alves Tapia. Os cursos de Fisioterapia no Paraná frente aos conceitos contemporâneos de saúde. 2002. 150 f. Dissertação (Mestrado em Saúde Coletiva)-Universidade Estadual de Londrina, Londrina, 2002.

SILVA, Luzia Wilma Santana da et al. Familia em contexto: multiversas abordagens em investigação qualitativa. 1. ed. Salvador: Arcádia, 2012.

SILVA, Luzia Wilma Santana da et al. Família, uma unidade de cuidado para seus membros: inquietações reflexivas. Revista SERVIR, Lisboa, v. 56, n. 5, p. 159-66, 2008.

SILVA, Daysi Jung da; DA ROS, Marco Aurélio. Inserção de profissionais de fisioterapia na equipe de saúde da família e Sistema Único de Saúde: desafios na formação. Revista Ciências \& Saúde Coletiva, Rio de Janeiro, v. 12, n. 6, p. 1673-1681, 2007.

SOARES, Daniela Arruda; SADIGURSKY, Dora. A competência interpessoal como elemento para o cuidado de enfermagem. Revista Saúde.com, Jequié, v. 5, n. 2, p. 147-155, 2009.

TORRES, Gilson de Vasconcelos et al. Funcionalidade familiar de idosos dependentes residentes em domicílios. Revista Avaliação Psicológica, Itatiba, v. 8, n. 3, p. 415-423, 2009.

TRIVIÑOS, Augusto Nibaldo Silva. Introdução à pesquisa em ciências sociais: a pesquisa qualitativa em educação. 1. ed. São Paulo: Atlas, 2009.

VALENÇA, Tatiane Dias Casimiro. Cuidar a família: a formação do fisioterapeuta para o alcance dos cuidados à pessoa idosa em estado de fragilidade no contexto domiciliário. 2011. 163 f. Dissertação (Mestrado em Enfermagem e Saúde)-Universidade Estadual do Sudoeste da Bahia, Jequié, BA, 2011. 

